Pesq. Vet. Bras. 38(1):41-47, janeiro 2018 DOI: $10.1590 / \mathrm{S} 0100-736 \mathrm{X} 2018000100007$

\title{
Prevalência de leptospirose em rebanhos bovinos no Pantanal de Mato Grosso do Sul ${ }^{1}$
}

\author{
Aline Fernanda Miashiro², Silvio Arruda Vasconcellos ${ }^{3}$, Zenaide Maria de Morais ${ }^{3}$, \\ Gisele Oliveira de Souza ${ }^{3}$, Jamil Manoel Leal Filho ${ }^{4}$, Aline de Oliveira Figueiredo ${ }^{5}$ \\ e Aiesca Oliveira Pellegrin ${ }^{6 *}$
}

\begin{abstract}
Miashiro A.F., Vasconcellos S.A., Morais Z.M., Souza G.O., Leal Filho J.M., Figueiredo A.O. \& Pellegrin A.O. 2018. [Prevalence of leptospirosis in cattle herds in the Pantanal of Mato Grosso do Sul.] Prevalência de leptospirose em rebanhos bovinos no Pantanal de Mato Grosso do Sul. Pesquisa Veterinária Brasileira 38(1):41-47. Embrapa Pantanal, Empresa Brasileira de Pesquisa Agropecuária, Rua 21 de Setembro 1880, Cx. Postal 109, Corumbá, MS 79320-900, Brazil. E-mail: aiesca.pellegrin@embrapa.br

This is an epidemiological study of leptospirosis in 24 month-old females from 246 herds. Two thousand, seven hundred and sixty six $(2,766)$ animals were randomly sampled in the nine counties comprising the region of Pantanal of Mato Grosso do Sul, Brazil. The risk factors associated with the disease were also identified. Blood samples were collected from September to November 2009 and examined by the microscopic agglutination test (MAT) against a collection of 24 live antigens of Leptospira spp., representatives of serovars Australis, Bratislava, Autumnalis, Butembo, Castellonis, Batavie, Canicola Whitcombi, Cynopteri, Grippotyphosa, Hebdomadis, Copenhageni, Icterohaemorrhagiae, Javanica, Panama, Pomona, Pyrogenes, Hardjo, Wolffi, Shermani, Tarassovi, Sentot, Andamana, and Patoc. Additionally, twelve representatives of Leptospira strains isolated in Brazil were added to the collection of antigens for the microscopic agglutination test (MAT). The apparent prevalence was $66 \%$ and the actual prevalence of infected animals was $79.80 \%$, with a confidence interval of $95 \%$ (78.3 to 81.3) and 241 herds having at least one reactive animal. The most likely serovars were Hardjo followed by Wolffi. Results show that bovine leptospirosis is still present in Pantanal, with high prevalence both in animals and herds, the main risk factors for the disease being the type of cattle farming and breeding.
\end{abstract}

INDEX TERMS: Leptospirosis, cattle, epidemiology, Pantanal, bacterioses.

\footnotetext{
${ }^{1}$ Recebido em 31 de agosto de 2016.

Aceito para publicação em 3 de abril de 2017

${ }^{2}$ Programa de Pós-Graduação em Ciência Animal, Faculdade de Medicina Veterinária e Zootecnia, Universidade Federal de Mato Grosso do Sul, Cidade Universitária, Av. Senador Filinto Müller 2443, Campo Grande, MS 79070-900, Brasil.

${ }^{3}$ Departamento de Medicina Veterinária Preventiva e Saúde Animal, Faculdade de Medicina Veterinária e Zootecnia, Universidade de São Paulo (USP), Cidade Universitária, Av. Prof. Dr. Orlando Marques Paiva 87, São Paulo, SP 05508-270, Brasil.

${ }^{4}$ Superintendência Federal de Agricultura, Ministério da Agricultura, Pecuária e Abastecimento, Rua Dom Aquino 2696, Bairro Centro, Campo Grande, MS 79002-182, Brasil.

${ }^{5}$ Agência Estadual de Defesa Sanitária (Iagro), Av. Sen. Filinto Müler 1146, Vila Ipiranga, Campo Grande, MS 79074-460, Brasil.

${ }^{6}$ Embrapa Pantanal, Rua 21 de Setembro 1880, Cx. Postal 109, Corumbá, MS 79320-900, Brasil.*Autor para correspondência: aiesca.pellegrin@ embrapa.br
}

RESUMO.- Foi realizado um estudo epidemiológico da leptospirose em fêmeas acima de 24 meses, provenientes de 246 rebanhos, e 2.766 animais amostrados aleatoriamente nos nove municípios que compõem a região do Pantanal de Mato Grosso do Sul, bem como identificados os fatores de risco associados à doença. As amostras de sangue foram coletadas no período de setembro a novembro de 2009 e examinadas pelo teste de aglutinação microscópica ante uma coleção de 24 antígenos vivos de Leptospira spp., representantes dos sorovares Australis, Bratislava, Autumnalis, Butembo, Castellonis, Batavie, Canicola, Whitcombi, Cynopteri, Grippotyphosa, Hebdomadis, Copenhageni, Icterohaemorrhagiae, Javanica, Panamá, Pomona, Pyrogenes, Hardjo, Wolffi, Shermani, Tarassovi, Sentot, Andamana e Patoc. Adicionalmente, representantes de doze estirpes de leptospiras isoladas no Brasil foram adicionados à cole- 
ção de antígenos do teste de soroaglutinação microscópica (SAM). A prevalência aparente foi de $66 \%$ e a prevalência real de animais infectados, de 79,80\%, com intervalo de confiança (IC) de 95\% (78,3-81,3) e 241 rebanhos apresentando pelo menos um animal reagente. Os sorovares mais prováveis foram o Hardjo seguido pelo Wolffi. Os resultados demonstram que a leptospirose bovina continua presente no Pantanal, com alta prevalência tanto em rebanhos quanto em indivíduos, sendo os principais fatores de risco para a doença o tipo de exploração e a raça.

TERMOS DE INDEXAÇÃO: Leptospirose, bovinos, epidemiologia, Pantanal, bacterioses.

\section{INTRODUÇÃO}

A leptospirose é uma doença de distribuição cosmopolita, já tendo sido diagnosticada em animais de todos os continentes e países, exceto nas regiões polares (Blaha 1995). A enfermidade tem alta prevalência em países de clima tropical em decorrência de fatores ambientais representados, principalmente, por grandes precipitações pluviais e tipo de solo: neutro ou alcalino (Acha \& Szyfres 1986).

O Pantanal Mato-Grossense é uma região que possui condições ecológicas de temperatura e pluviosidade altamente favoráveis à ocorrência da leptospirose bovina (Faine 1982, Garcia \& Castro 1986, Lins et al. 1986). A evidência sorológica da infecção pela Leptospira spp. já tem sido comprovada no Mato Grosso do Sul em inquérito epidemiológico no qual foi estimada a prevalência de $96,5 \%$ de rebanhos positivos e em $98,8 \%$ de fêmeas em idade reprodutiva (Figueiredo et al. 2009). No Pantanal, estudos soroepidemiológicos estimaram frequências de anticorpos para Leptospira spp. tanto em bovinos de corte (Pellegrin et al. 1992, 1999) quanto em animais silvestres (Mathias et al. 1999, Girio et al. 2004, Vieira et al. 2011), sendo detectado que o sorovar Hardjo, amostra CTG (Cantagalo) (Pellegrin et al. 1999), é o mais provável em bovinos, e os sorovares Wolffi e Pomona, em veados campeiros; estes últimos também foram encontrados, respectivamente, por Girio et al. (2004) e Vieira et al. (2011).

Levantamentos epidemiológicos para estimativas de prevalência que permitam inferências para uma dada população e tomada de decisão devem basear-se em amostragem probabilística desenhada para tal finalidade, sendo o tamanho da amostra baseado na prevalência esperada, nível de confiança e no erro aceitável (Medronho et al. 2009). A execução de inquéritos transversais demanda elevado aporte de recursos materiais, humanos e financeiros, visto que as coletas devem ser executadas no menor prazo de tempo possível, sendo que a otimização do uso das amostras obtidas para ampliar o conhecimento do estado sanitário dos rebanhos tem sido uma prática cada vez mais comum (Castro et al. 2008, Oliveira et al. 2010, Hashimoto et al. 2012, Silva et al. 2012).

A identificação dos sorovares mais prováveis nos rebanhos estudados é fundamental para a tomada de decisão quanto à melhor estratégia de controle, principalmente no que se refere à escolha da composição dos imunógenos a serem utilizados. Nos diversos levantamentos soroepidemiológicos realizados em bovinos, a predominância de re- ações para o sorovar Hardjo tem confirmado essa espécie como o hospedeiro preferencial deste sorovar (Ellis 1994), atuando como seu reservatório e disseminador junto à população susceptível (Armatredjo \& Campbell 1975).

A inclusão de amostras isoladas no País (autóctones) em coleções de antígenos utilizadas no diagnóstico da leptospirose tem demonstrado aumentar a sensibilidade do teste de soroaglutinação microscópica. Os títulos observados para as estirpes autóctones são geralmente mais elevados que os sorovares de referência mantidos em laboratório (Levett 2001, Oliveira 2003, Sarmento et al. 2012).

0 abortamento é a principal manifestação clínica da leptospirose crônica em rebanhos bovinos e, frequentemente, o único sinal observado. Em propriedades com grande número de animais, distribuídos em áreas extensas e com poucas subdivisões, ele dificilmente é registrado, permitindo a manutenção do agente no rebanho, o que foi apontado em recente levantamento realizado no estado do Mato Grosso do Sul (Figueiredo et al. 2009).

0 objetivo deste estudo foi estimar a prevalência de anticorpos anti-Leptospira em uma amostragem probabilística de rebanhos e fêmeas bovinas em idade reprodutiva, oriundas de rebanhos bovinos da região do Pantanal, bem como identificar os principais fatores de risco relacionados à doença.

\section{MATERIAL E MÉTODOS}

O estudo foi realizado na região do Pantanal de Mato Grosso do Sul, em uma área composta por nove municípios e 6.320 propriedades, apresentando um total de 2.157.468 fêmeas com mais de 24 meses. Essa região foi denominada Estrato 1 do Estado de Mato Grosso do Sul (MS) na estratificação utilizada para a realização do inquérito epidemiológico para brucelose e tuberculose, cujas amostras foram utilizadas também no presente trabalho. 0 Pantanal sul-mato-grossense é constituído por uma área de 70.215 $\mathrm{km}^{2}$, o que representa 19,7\% do Estado de Mato Grosso do Sul (Brasil 2003), sendo considerada uma região eminentemente de cria de bezerros em virtude de suas peculiaridades ambientais.

Amostragem. Para o estrato do Pantanal, foi realizada uma amostragem aleatória de rebanhos baseada em uma prevalência esperada de $80 \%$, adaptada de Favero et al. (2001), nível de confiança de $95 \%$ e erro de 5\%, totalizando amostras de 246 propriedades. A amostragem foi realizada em dois estágios, sendo o rebanho considerado a unidade primária e os animais dentro de cada rebanho, as unidades secundárias (Noordhuizen et al. 1997).

No sorteio das propriedades, utilizou-se a listagem das fichas sanitárias fornecidas pela Agência Estadual de Defesa Sanitária Animal e Vegetal (Iagro) e metodologia de amostragem descrita por Figueiredo et al. (2009).

A seleção das fêmeas foi efetuada de forma aleatória, empregando-se o método de amostragem aleatória simples ou sistemática. A escolha por um dos métodos foi definida dividindo o total de fêmeas com idades iguais ou superiores a dois anos, existentes na propriedade, pelo total de fêmeas a serem amostradas. Para resultados inferiores a dois, empregou-se o método de amostragem aleatória simples; nos casos em que o resultado foi superior a dois, empregou-se o método de amostragem aleatória sistemática. Embora a amostragem tenha indicado um número de 2.601 fêmeas a serem colhidas, foram testados 2.766 animais, visando garantir problemas relativos à perda de amostras.

As amostras de sangue foram colhidas no período de setembro a novembro de 2009, por punção jugular, com agulha descar- 
tável, uma para cada animal, e transportadas para o Laboratório de Diagnóstico de Doenças Animais (Laddan), da Agência Estadual de Defesa Sanitária Animal e Vegetal de Mato Grosso do Sul (Iagro). Os soros obtidos foram estocados a $-20^{\circ} \mathrm{C}$ e depois submetidos ao teste de soroaglutinação microscópica (SAM) de leptospirose, no Laboratório de Zoonoses bacterianas da Faculdade de Medicina Veterinária e Zootecnia, Universidade de São Paulo (FMVZ/USP).

Para a realização do diagnóstico de leptospirose foi utilizada a técnica descrita anteriormente por Galton et al. (1965) e Cole et al. (1973), empregando uma coleção de antígenos vivos composta por representantes de 22 sorovares patogênicos (Australis, Bratislava, Autumnalis, Butembo, Castellonis, Batavie, Canicola, Whitcombi, Cynopteri, Grippotyphosa, Hebdomadis, Copenhageni, Icterohaemorrhagiae, Javanica, Panama, Pomona, Pyrogenes, Hardjo, Wolffi, Shermani, Tarassovi e Sentot) e dois sorovares saprófitas (Andamana, Patoc). Esses antígenos compõem a coleção utilizada no diagnóstico de rotina do Laboratório de Zoonoses Bacterianas da Universidade de São Paulo. Visando aumentar a sensibilidade de detecção da infecção na região estudada, foi também utilizada uma coleção de antígenos vivos representantes de 12 sorovares patogênicos, isolados de animais domésticos e silvestres provenientes de várias regiões do Brasil (Brasiliensis, Pomona, Guaricura, Copenhageni, Canicola (canino), Canicola (suíno), Canicola (bovino), Bananal (capivara), Pomona (suíno) e uma provável espécie nova, ainda não identificada, a primeira isolada, obtida no Pantanal, da espécie Cerdocyum thous (lobinho) na mesma região de estudo desse trabalho. Os antígenos foram mantidos a $28{ }^{\circ} \mathrm{C}$ em estufa bacteriológica BOD, de 5 a 15 dias, em meio suplementado com soro de coelho, preparado no próprio laboratório. As culturas não apresentavam contaminação e autoaglutinação.

Para a detecção da presença de anticorpos contra Leptospira spp. utilizou-se a técnica de soroaglutinação microscópica. Primeiro, as amostras passaram por uma triagem, na qual foram consideradas reagentes amostras com diluição igual ou superior a 1:100, com mínimo de 50\% de aglutinação em microscopia de campo escuro. Após a triagem, as amostras reagentes foram tituladas. Para determinação do sorovar mais provável, foram considerados aqueles que apresentaram maior título, sendo desconsiderados da análise quando o título mais alto foi idêntico para dois ou mais sorovares (Vasconcellos et al. 1997).

Análise dos dados. As prevalências, aparente $(\mathrm{Pa})$ e real
(Pr) para animais, bem como o intervalo de confiança (IC), foram calculadas conforme Martin et al. (1987). A Pr foi estimada ajustando-se o valor de $\mathrm{Pa}$ obtido para a especificidade $(0,97)$ e sensibilidade $(0,82)$ do teste de SAM utilizadas anteriormente por Figueiredo et al. (2009).

Foram estimadas a prevalência aparente de rebanho (PaR), de acordo com Martin et al. (1987), e os intervalos de confiança das prevalências aparente e real de animais e de rebanhos foram calculados para uma confiança de $95 \%$, de acordo com os mesmos autores.

Questionário. Em cada propriedade amostrada, foram realizadas entrevistas com a finalidade de levantar os fatores de risco para a doença na região estudada. As variáveis de risco foram distribuídas em uma tabela e analisadas pelo teste de Qui Quadrado $\left(\chi^{2}\right)$ ou pelo teste exato de Fisher, quando indicado (Sampaio 1998). As variáveis analisadas compreendiam tipo de exploração (corte, leite, misto), raça dos animais (zebu, europeu de leite, europeu de corte, outras), número de matrizes com idades iguais ou superiores a 24 meses, tipo de criação (extensivo, intensivo, semiconfinado), uso de pasto comum e arrendamento de pasto, piquete maternidade, dentre outras.

\section{RESULTADOS}

A prevalência aparente de rebanhos foi de 98\%, com 241 dos 246 rebanhos testados apresentando pelo menos um animal positivo ao teste de soroaglutinação microscópica. A prevalência real de rebanhos foi de $97 \%$, considerando-se uma sensibilidade de rebanho e especificidade de rebanho de $100 \%$ e $69,4 \%$, respectivamente. A prevalência aparente de animais foi de $66 \%$, e a prevalência real de animais infectados foi de $79,80 \%$, com intervalo de confiança de $95 \%$ (78,3-81,3), considerando-se uma sensibilidade e especificidade individual do teste de soroaglutinação microscópica, respectivamente, de $82 \%$ e $97 \%$. Foram estimados os valores preditivos positivo e negativo de rebanho para rebanho, respectivamente, de $99,07 \%$ e $81,30 \%$, e de animais, respectivamente, de $99,07 \%$ e $57,7 \%$.

Nos Quadros 1 e 2 são identificados os sorovares mais prevalentes, tanto os incluídos na coleção de antígenos recomendada pela Organização Mundial de Saúde (OMS) quanto os detectados por meio da utilização de uma cole-

\section{Quadro 1. Rebanhos e animais reagentes no teste de soroaglutinação microscópica para leptospirose e suas variantes sorológicas mais prováveis, no ano de 2009 , nos municípios que compõem a região do Pantanal sul-mato-grossense, utilizando a coleção de antígenos recomendada pela OMS}

\begin{tabular}{|c|c|c|c|c|c|c|c|c|c|c|c|c|c|}
\hline \multirow[t]{2}{*}{ Municípios } & \multicolumn{3}{|c|}{$\mathrm{N}^{\circ}$ de reagentes } & \multicolumn{9}{|c|}{ Sorovares mais prováveis $(\%)$ a** } & \multirow[b]{2}{*}{$\begin{array}{l}\text { Autu- } \\
\text { mnalis }\end{array}$} \\
\hline & $\begin{array}{l}\text { Rebanhos } \\
\text { reagentes }^{\mathrm{b}}\end{array}$ & $\begin{array}{l}\text { Animais } \\
\text { reagentes }^{c}\end{array}$ & $\begin{array}{c}\text { Mais } \\
\text { prováveis* }\end{array}$ & Hardjo & Wolffi & $\begin{array}{l}\text { Icterohae- } \\
\text { morrhagiae }\end{array}$ & $\begin{array}{l}\text { Grippo- } \\
\text { typhosa }\end{array}$ & Bratislava & $\begin{array}{l}\text { Copenha- } \\
\text { geni }\end{array}$ & $\begin{array}{l}\text { Cani- } \\
\text { cola }\end{array}$ & $\begin{array}{l}\text { Hebdo- } \\
\text { madis }\end{array}$ & Pomona & \\
\hline Aquidauana & 41 & 327 & 99 & 28,4 & 14,3 & 0,31 & 5,81 & 0,31 & 1,5 & 0,0 & 3,9 & 0,6 & 0,0 \\
\hline Bodoquena & 27 & 198 & 66 & 31,8 & 16,1 & 0,0 & 4,55 & 0,0 & 0,0 & 0,0 & 2,0 & 1,0 & 0,0 \\
\hline Corumbá & 25 & 224 & 27 & 47,3 & 8,0 & 0,0 & 0,0 & 0,0 & 0,0 & 0,0 & 3,6 & 0,4 & 0,4 \\
\hline Coxim & 36 & 294 & 93 & 22,1 & 22,8 & 1,70 & 4,42 & 1,70 & 0,0 & 0,0 & 2,7 & 0,3 & 0,0 \\
\hline Ladário & 6 & 11 & 1 & 63,6 & 9,1 & 0,0 & 0,0 & 0,0 & 0,0 & 0,0 & 0,0 & 0,0 & 0,0 \\
\hline Miranda & 25 & 173 & 38 & 23,7 & 23,7 & 2,31 & 1,73 & 0,0 & 0,6 & 0,0 & 3,4 & 0,0 & 0,6 \\
\hline Porto & 30 & 276 & 96 & 10,9 & 19,6 & 0,0 & 3,26 & 0,3 & 0,0 & 0,0 & 3,6 & 1,1 & 0,0 \\
\hline \multicolumn{14}{|l|}{ Murtinho } \\
\hline Rio Verde & 40 & 272 & 92 & 38,9 & 7,7 & 0,74 & 2,57 & 0,3 & 0,0 & 0,0 & 2,2 & 0,3 & 0,0 \\
\hline Sonora & 11 & 51 & 12 & 5,9 & 50,9 & 0,0 & 0,0 & 13,7 & 0,0 & 0,0 & 1,9 & 3,9 & 0,0 \\
\hline
\end{tabular}

Totais $\quad 241$

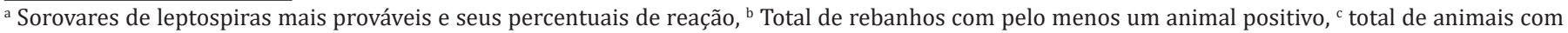
reação para pelo menos um sorovar; * número de reações aproveitadas, sendo desconsideradas aquelas com título mais alto idêntico para dois ou mais sorovares, ${ }^{* *}$ percentual de reações por sorovar, considerando apenas os reagentes mais prováveis. Fonte: elaborada pelos autores.
} 
Quadro 2. Rebanhos e animais reagentes, por município, no teste de soroaglutinação microscópica para leptospirose no Pantanal de Mato Grosso do Sul e suas variantes sorológicas mais prováveis em 246 rebanhos e 2.766 animais, no ano de 2009, utilizando uma coleção de antígenos composta de estirpes de leptospiras isoladas no Brasil

\begin{tabular}{|c|c|c|c|c|c|c|c|c|c|c|c|c|}
\hline \multirow[t]{2}{*}{ Municípios } & \multicolumn{3}{|c|}{ № de reagentes } & \multicolumn{9}{|c|}{ Estirpes isoladas no Brasil mais prováveis (\%) ${ }^{a * *}$} \\
\hline & $\begin{array}{l}\text { Rebanhos } \\
\text { reagentes }\end{array}$ & $\begin{array}{c}\text { Animais } \\
\text { reagentes }\end{array}$ & $\begin{array}{c}\text { Mais } \\
\text { prováveis* }\end{array}$ & $\begin{array}{c}4-\mathrm{B} \text { (VPS) } \\
\text { (An } 776 \text { original) }\end{array}$ & M 7-87 & M 4/98 & M 9/99 & LO-1 & $\mathrm{LO}-4$ & LO 14 & 2 A CAP & M 110/2006 \\
\hline Aquidauana & 41 & 327 & 99 & 0,0 & 0,0 & 2,4 & 0,3 & 0,3 & 1,5 & 1,2 & 0,6 & 0,0 \\
\hline Bodoquena & 27 & 198 & 66 & 0,0 & 0,0 & 0,0 & 0,0 & 1,0 & 0,51 & 0,0 & 0,0 & 0,0 \\
\hline Corumbá & 25 & 224 & 27 & 0,0 & 0,0 & 1,3 & 0,0 & 0,4 & 0,0 & 2,3 & 0,0 & 0,4 \\
\hline Coxim & 36 & 294 & 93 & 0,0 & 0,0 & 2,0 & 0,0 & 0,7 & 1,3 & 0,7 & 0,3 & 0,0 \\
\hline Ladário & 6 & 11 & 1 & 0,0 & 0,0 & 0,0 & 0,0 & 9,1 & 0,0 & 9,1 & 0,0 & 0,0 \\
\hline Miranda & 25 & 173 & 38 & 0,0 & 0,0 & 2,9 & 0,6 & 0,6 & 0,5 & 0,5 & 0,0 & 1,1 \\
\hline $\begin{array}{l}\text { Porto } \\
\text { Murtinho }\end{array}$ & 30 & 276 & 96 & 0,0 & 0,0 & 0,0 & 0,7 & 1,8 & 5,8 & 1,4 & 0,0 & 0,0 \\
\hline Rio Verde & 40 & 272 & 92 & 0,0 & 0,0 & 0,3 & 0,7 & 0,3 & 2,2 & 0,7 & 0,3 & 0,0 \\
\hline Sonora & 11 & 51 & 12 & 0,0 & 0,0 & 0,0 & 0,0 & 0,0 & 0,0 & 0,0 & 0,0 & 0,0 \\
\hline Totais & 241 & 1826 & 524 & & & & & & & & & \\
\hline
\end{tabular}

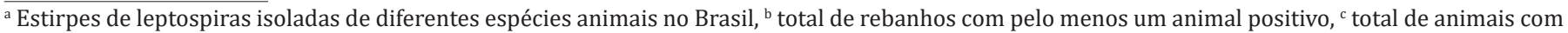
reação para pelo menos um sorovar; * número de reações aproveitadas, sendo desconsideradas aquelas com título mais alto idêntico para dois ou mais sorovares, ** percentual de reações por sorovar, considerando apenas os reagentes mais prováveis. Fonte: Elaborada pelos autores.

Quadro 3. Prevalência aparente e real, especificidade e sensibilidade e valores preditivos e rebanhos e animais amostrados em inquérito sorológico realizado para a leptospirose bovina em matrizes na região do Pantanal de Mato Grosso do Sul em 2009

\begin{tabular}{ccccccc}
\hline PrevApaR & PrevRR & IC* & SeR & EspR & VPPR & VPNR \\
\hline $98 \%$ & $97 \%$ & $(94,9-99,2)$ & $100 \%$ & $69 \%$ & $99,07 \%$ & $81,30 \%$ \\
PrevAA & PrevRA & IC** & Se & Esp & VPP & VPN \\
$66 \%$ & $79,80 \%$ & $(78,3-81,3)$ & $82 \%$ & $97 \%$ & $99,07 \%$ & $57,7 \%$
\end{tabular}

PrevApaR = Prevalência Aparente de Rebanhos, PrevRR = Prevalência Real de Rebanhos, IC* = Intervalo de Confiança para Prevalência de Rebanhos, SeR = Sensibilidade de Rebanhos, EspR = Especificidade de Rebanhos, VPPR = Valor Preditivo Positivo de Rebanho, VPNR = Valor Preditivo Negativo de Rebanho, PrevAA = Prevalência Aparente de Animais, PrevRA = Prevalência Real de Animais, IC ${ }^{* *}=$ Intervalo de confiança para Prevalência de Rebanhos, $\mathrm{Se}=$ Sensibilidade do teste aplicado em animais, Esp= Especificidade do teste aplicado em animais, VPP= Valor Preditivo Positivo do teste aplicado em animais, VPN= Valor Preditivo Negativo do teste aplicado em animais. Fonte: Elaborada pelos autores.

ção de antígenos composta de isolados de leptospiras de várias espécies animais do Brasil e depositadas na coleção da Universidade de São Paulo.

Os sorovares mais prevalentes, detectados segundo a coleção recomendada pela OMS (Quadro 1), dentre os mais prováveis foram o Hardjo, com percentuais de animais reagentes variando de 5,88\% (Sonora) a 63,64\% (Ladário) e o sorovar Wolffi, cujos percentuais de reações detectadas variaram de 7,72\% (Rio Verde) a 59,98\% (Sonora). Quando os soros foram testados ante a coleção de antígenos composta pelas estirpes autóctones, foram detectadas reações para M4/98, M9/99, LO-1, L04, LO 14, 2CAP em diversos municípios, mas em percentuais bastante baixos. Entretanto, para o isolado obtido na região de estudo, da espécie Cerdocyum thous, M110/2006, somente reagiram soros provenientes de propriedades dos municípios de Corumbá e de Miranda (Quadro 2).

No Quadro 3 são apresentadas as estimativas de prevalência aparente e real de rebanhos e de animais com ajuste realizado pelas características do teste empregado e sua capacidade de classificação correta de animais (sensibili-
Quadro 4. Fatores de risco para a leptospirose nos rebanhos estudados que apresentaram $p<0,20$ na análise univariada $e$ seus respectivos valores de odds ratio (OR)

\begin{tabular}{|c|c|c|c|c|}
\hline Fator de risco ${ }^{a}$ & Negativos ${ }^{b}$ & Positivos $^{c}$ & $P^{d}$ & $\mathrm{OR}^{\mathrm{e}}$ \\
\hline \multicolumn{5}{|l|}{ Exploração } \\
\hline Corte & 4 & 150 & 0,04 & $5,92(1,23-8,50)$ \\
\hline Leite & 3 & 19 & 0,01 & $0,29(0,05-1,91)$ \\
\hline Mista & 2 & 43 & 0,625 & $1,74(0,31-0,85)$ \\
\hline \multicolumn{5}{|l|}{ Tipo de propriedade } \\
\hline Chácara/lote/sítio & 6 & 56 & 0,0160 & $5,57(1,35-3,03)$ \\
\hline Fazenda & 3 & 156 & & \\
\hline \multicolumn{5}{|l|}{ Presença de equinos } \\
\hline Sim & 4 & 185 & 0,039 & $8,56(2,16-3,89)$ \\
\hline Não & 5 & 27 & & \\
\hline \multicolumn{5}{|l|}{$\begin{array}{l}\text { Presença de ovinos } \\
\text { e caprinos }\end{array}$} \\
\hline Sim & 7 & 107 & 0,17 & $0,29(0,06-1,43)$ \\
\hline Não & 2 & 105 & & \\
\hline \multicolumn{5}{|l|}{$\begin{array}{l}\text { № de fêmeas em } \\
\text { reprodução }\end{array}$} \\
\hline$<=100$ & 8 & 119 & 0,0820 & $0,16(0,02-1,30)$ \\
\hline$>=100$ & 1 & 93 & & \\
\hline \multicolumn{5}{|l|}{ Raças } \\
\hline Zebu & 3 & 156 & 0,0160* & $5,57(1,35-3,03)$ \\
\hline Mestiço/Europeu/ & 6 & 56 & & \\
\hline
\end{tabular}

outras

a Fatores de risco que apresentaram $\mathrm{p}<0,20$ na análise univariada, ${ }^{\mathrm{b}}$ rebanhos negativos para o fator de risco, ${ }^{\mathrm{c}}$ rebanhos positivos para o fator de risco, ${ }^{d}$ Nível de significância, ${ }^{\text {e }}$ Odds Ratio estimado e seu intervalo de confiança. Fonte: elaborada pelos autores.

dade do teste), ou de rebanhos doentes (sensibilidade de rebanho), ou de animais ou rebanhos sadios (especificidade do teste/especificidade de rebanho), por meio da detecção individual.

Os fatores de risco identificados, de qui quadrado ou teste exato de Fisher, conforme o caso ( $p>=0,2)$, e subsequente estimativa do odds ratio, foram considerados significativos e estão agrupados no Quadro 4.

\section{DISCUSSÃO}

Nos nove municípios que compõem a região do Pantanal sul-mato-grossense, foram detectados rebanhos e animais 
sororreagentes para a leptospirose bovina. A prevalência aparente de rebanhos foi de 98\%, com 241 dos 246 rebanhos testados apresentando pelo menos um animal positivo no teste de SAM. A prevalência real de rebanhos, ajustada para a SenR (100\%) e EspR (69,4\%), foi de $97 \%$. A prevalência aparente de animais foi de $66 \%$, sendo também ajustada considerando-se uma sensibilidade e especificidade individual da SAM respectivamente de $82 \%$ e $97 \%$, estimando a prevalência real de animais infectados em 79,80\% com IC de 95\% (78,3-81,3).

Resultado semelhante foi observado por Favero et al. (2001) no estado de Mato Grosso do Sul, onde 100\% dos municípios apresentaram pelo menos um animal sororreagente em todos os rebanhos amostrados. Ao estudar a relação epidemiológica existente entre duas populações simpátricas de mamíferos no Pantanal do Mato Grosso do Sul, bovinos e porco-monteiros, Fontana (2011) amostrou 12 propriedades e testou 266 amostras, encontrando um percentual de soropositividade para a leptospirose de 76,69\% (204), com maior ocorrência de reações para os sorovares Hardjo, Tarassovi e Grippotyphosa. Entretanto, a prevalência dos sorovares Icterohaemorrhagiae e Pomona nos bovinos foi de apenas 3,75\% e 3\%, respectivamente, embora nos suínos ferais estes tenham sido os sorovares mais frequentes.

A prevalência de leptospirose bovina nos rebanhos amostrados no presente inquérito foi a mesma encontrada em outros inquéritos transversais com desenho amostral similar, como os conduzidos por Aguiar et al. (2006), no município de Monte Negro, Rondônia, com 95,3\% (IC 95\%: 88,5-98,7\%), e por Homem et al. (2000), no município de Uruará, Pará, que estimaram prevalência de rebanho também elevada, com 97\% (IC 95\%: 90,9-99,5\%). Oliveira et al. (2010), no Estado da Bahia, estimaram as prevalências de rebanho e individual em 77,93\% e 45,2\%, respectivamente, com base em uma amostragem de diferentes regiões do estado. Os resultados indicaram que as prevalências diferiram significativamente de acordo com os circuitos pecuários avaliados. No presente trabalho evidenciou-se a predominância de reações para os sorovares Hardjo (Hardjoprajitno) em 34,39\% dos rebanhos e fatores de risco tais como: compra de reprodutores, presença de suínos e cervídeos na propriedade, áreas alagadiças, aluguel de pasto e raças especializadas compondo o rebanho.

0 inquérito realizado por Figueiredo et al. em 2009 em outro estrato do Mato Grosso do Sul, composto de 22 municípios, revelou a presença de fêmeas em reprodução sororreagentes em 85\% dos rebanhos (161) e 98,8\% dos animais (1.801). Os ICs (95\%) para a prevalência aparente e real de rebanhos foi de $90,4 \%$ (IC $95 \%$ : 95,1\%-85,8\%) e 85,2\% (IC 95\%: 80,1\%-90,2\%). A prevalência de animais foi de $81,1 \%$, sendo os sorovares mais dominantes o Hardjo $(65,6 \%)$, seguido do sorovar Wolffi $(12,3 \%)$, semelhante ao encontrado no presente trabalho. Deve-se ressaltar que, para Figueiredo et al. (2009), o ponto de corte utilizado para classificar um rebanho como positivo foi o achado de quatro animais reagentes a partir do teste SAM, enquanto que, no presente estudo, foi de apenas um animal. Assim, como os inquéritos acima citados, o presente trabalho é o primeiro desenhado com o objetivo de estimar a prevalência da leptospirose em fêmeas em reprodução no Pantanal, destacando-se sua importância pelo fato de essa região ser eminentemente de cria, tendo no bezerro desmamado seu principal produto. Dessa forma, investigações que permitam inferências sobre possíveis causas de perdas reprodutivas podem ter uma aplicação no estabelecimento de um calendário sanitário profilático que otimize a fertilidade do rebanho.

A utilização de estirpes autóctones, tanto para uso como antígenos no diagnóstico sorológico quanto para a produção de vacinas, é uma forma de aumentar a acurácia do teste de SAM, minimizando a ocorrência de animais falso-negativos e falso-positivos, metodologia que tem sido utilizada por alguns autores no diagnóstico de leptospirose em bovinos (Sarmento et al. 2012) e em animais silvestres (Vieira et al. 2011, 2013). Na soroaglutinação microscópica para leptospirose, a coleção de estirpes empregadas como antígenos, idade e densidade dos cultivos, diluição final dos soros, temperatura e tempo de incubação são fatores que influenciam diretamente na obtenção dos resultados (Noordhuizen et al. 1997, Sarmento et al. 2012). O presente trabalho utilizou, além da coleção de antígenos recomendada pela OMS, uma coleção complementar de isolados autóctones. Um dos antígenos empregados na coleção de sorovares autóctones foi isolado de um Cerdocyum thous capturado na mesma região onde foi realizado o presente trabalho. 0 uso da coleção de isolados autóctones não pareceu agregar maior sensibilidade à detecção dos animais sorologicamente positivos, apesar de Sarmento et al. (2012) detectarem uma elevação de $6 \%$ de reações encontradas para a leptospira quando a coleção de antígenos convencionalmente empregada era ampliada com a agregação dos sorovares autóctones, posicionando o sorovar Guaricura como o mais reagente nos soros testados provenientes do estado de Mato Grosso do Sul, seguido pelos sorovares Hardjo e Shermani. Nesse trabalho, os sorovares Hardjo e Wolffi foram os mais prevalentes, sugerindo que a leptospira mantém-se na população bovina de forma autossustentável, pois nem mesmo o antígeno autóctone (M110/2006) isolado em animal silvestre na própria região de estudo foi detectado de forma significativa na população. 0 sorovar Hardjo já foi isolado de bovinos no Brasil, sendo também tipificado por Moreira (1994). Apesar disso, não há registros no Brasil de isolamento do sorovar Wolffi a partir de bovinos, já tendo havido isolamentos de roedores silvestres (Akodon arviculoides) (Correa et al. 1965/1967), camundongos (Mus musculus) (Giorgi et al. 1984) e mesmo do homem (Correa et al. 1965/1967). A manutenção da doença dentro da própria população bovina também pode ser concluída pelos resultados apresentados por Fontana (2011), que demonstrou que os sorovares mais frequentes em bovinos são registrados em baixíssimos níveis em suínos ferais, mesmo vivendo em simpatria. No mesmo trabalho, realizado em parte da mesma área de estudo no Pantanal do Mato Grosso do Sul, foram detectados níveis de positividade de $47,74 \%$ para o sorovar Hardjo em bovinos e somente $0,66 \%$ para suínos ferais, enquanto que, nessa última população os sorovares mais frequentes foram Ic- 
terohaemorrhagiae $(44,37 \%)$ e Pomona $(19,2 \%)$, sorovar este também encontrado com maior frequência em veados campeiros por Vieira et al. (2011).

Os sorovares Hardjo e Wolffi têm sido identificados como os mais prevalentes em bovinos em inúmeros trabalhos, como os realizados por Favero et al. (2001), que abrangeu 21 estados do Brasil, por Lilenbaum e Souza (2003), no Rio de Janeiro, com frequências de animais reagentes de $43,8 \%$ para o sorovar Hardjo e $24,7 \%$ para o Wolffi e, na mesma área de estudo, por Pellegrin et al. em 1999, tanto em animais quanto em rebanhos.

Trabalho com desenho experimental semelhante, mas com abrangência para todo o estado de São Paulo, foi realizado por Castro et al. em 2008, permitindo uma estimativa da prevalência de leptospirose tanto em rebanhos quanto em animais, identificando os sorovares Hardjo (46\%) e Wolffi (21\%), associados, como os de maior frequência, seguidos pelos sorovares Shermani $(8,9 \%)$, Autumnalis $(4,4 \%)$ e Grippotyphosa (3,9\%).

No presente trabalho, o levantamento de fatores de risco associados à leptospirose envolveu principalmente o tipo de propriedade (OR 5,57 [1,35-3,03]; $p=0,0160$ ), a raça zebuína (OR 5,57 [1,35-3,03]; $\mathrm{p}=0,0160$ ) e o tipo de exploração de corte (OR 5,92 [1,23-8,50]; $p=0,04)$, embora fatores aparentemente significativos, como presença de equinos (OR 8,56 (2,16-3,89; p=0,039), também possam ser associados ao tamanho de rebanho e tipo de exploração, dado que, em propriedades de maiores dimensões, o manejo do rebanho depende do cavalo de montaria e nelas são mantidos grandes rebanhos equinos. Figueiredo et al. (2009) encontrou associação positiva entre o tipo de criação e raça e a presença de anticorpos para a leptospirose, indicando que a doença tem maior risco de ocorrer em grandes rebanhos. As mesmas conclusões foram consideradas por Castro et al. (2008). Estes autores também apontaram uma distribuição da doença em todo o estado, sem significativa associação aos fatores de risco, evidenciando que o sorovar Hardjo está amplamente distribuído no estado de São Paulo, sem relação com o tipo de exploração, manejo e práticas de reprodução adotados nos rebanhos. Outras variáveis estudadas, como a presença de áreas alagadiças na propriedade, presença de animais silvestres, assistência veterinária, presença de suínos, caprinos ou ovinos, bem como disponibilidade, ou não, de assistência veterinária, também não demonstraram nenhuma associação com a prevalência da doença, provavelmente porque o levantamento realizado por meio do questionário para essas variáveis teve uma abordagem qualitativa e foi realizado em uma época considerada seca, quando tanto a precipitação pluviométrica quanto a distribuição espacial de áreas alagadiças são reduzidas.

A leptospirose bovina encontra-se presente em todos os municípios estudados, observando-se alta prevalência tanto em animais como em rebanhos, com pelo menos um animal reagente à prova sorológica. Apesar de os sorovares Hardjo e Wolffi serem os mais prevalentes neste trabalho, não são os únicos a circularem na população bovina da região, devendo isto ser considerado para aplicação de práticas de profilaxia e controle da doença.
Agradecimentos.- Ao Conselho Nacional de Desenvolvimento Científico e Tecnológico (CNPq), à Superintendência Federal de Agricultura, MS, Ministério da Agricultura, Pecuária e Abastecimento. Ao Governo do Estado de Mato Grosso do Sul por meio da Fundação de Apoio ao Desenvolvimento do Ensino, Ciência e Tecnologia do Estado de Mato Grosso do Sul e do apoio recebido da Agência Estadual de Defesa Sanitária Animal e Vegetal (Iagro).

\section{REFERÊNCIAS}

Acha P.N. \& Szyfres B. 1986. Zoonosis y enfermedades transmisibles comunes al hombre y a los animales. 2nd ed. Organización Panamericana de la Salud, Washington, DC.

Aguiar D.M., Gennari S.M., Cavalcante G.T., Labruna M.B., Vasconcellos S.A., Rodrigues A.A.R., Moraes Z.M. \& Camargo L.M.A. 2006. Seroprevalence of Leptospira spp. in cattle from Monte Negro Municipality, Western Amazon, Brazil. Pesq. Vet. Bras. 26(2):102-104.

Armatredjo A. \& Campbell R.S.F. 1975. Bovine Leptospirosis. Vet. Bull. 43:875-891.

Blaha T. 1995. Epidemiología especial veterinaria. Acribia, Zaragoza, Espanha, p.128-136.

Brasil 2003. Resolução № 5, de 10 de outubro de 2002, que dispõe sobre a Área Territorial. Ministério do Planejamento, Orçamento e Gestão, Diário Oficial da República Federativa do Brasil, Brasília, DF, 198:48-65.

Castro V., Azevedo S.S., Gotti T.B., Batista C.S.A., Gentili J., Moraes Z.M., Souza G.O., Vasconcellos S.A. \& Genovez M.E. 2008. Soroprevalência da leptospirose em fêmeas bovinas em idade reprodutiva no Estado de São Paulo, Brasil. Arqs Inst. Biol. 75(1):3-11.

Cole Junior J.R., Sulzer C.R. \& Pursell A.R. 1973. Improved microtechnique for the leptospiral microscopic agglutination test. J. Appl. Microbiol. 25:970-980

Correa M.O.A., Hyakutake S., Natale V., Galvão P.A. \& Aguiar H.A. 1965/1967. Estudos sobre a Leptospira Wolffi, em São Paulo. Revta Inst. Adolfo Lutz 25/27:11-25. (Apud Sarmento et al. 2012)

Ellis W.A. 1994. Leptospirosis as a cause of reproductive failure. Vet. Clin. N. Am., Food Anim. Pract. 10:463-478.

Faine S. 1982. Guidelines for the control of leptospirosis. WHO off-set publication 67, Geneva, 171p.

Favero M., Pinheiro S.R., Vasconcellos S.A., Morais Z.M., Ferreira F. \& Ferreira Neto J.S. 2001. Leptospirose bovina: variantes sorológicas predominantes em colheitas efetuadas no período de 1984 a 1997 em rebanhos de 21 estados do Brasil. Arqs Inst. Biológico, São Paulo, 68(2):29-35.

Figueiredo A.O., Pellegrin A.O., Gonçalves V.S.P., Freitas E.B., Monteiro L.A.R.C., Oliveira J.M. \& Osório L.A.R. 2009. Prevalência e fatores de risco para a leptospirose em bovinos de Mato Grosso do Sul. Pesq. Vet. Bras. 29(5):375-381.

Fontana I. 2011. Avaliação do papel do porco monteiro na cadeia epidemiológica da leptospirose em sub-regiões do Plantanal sul-mato-grossense. Dissertação de Mestrado em Saúde Animal, Faculdade de Agronomia e Medicina Veterinária, Universidade de Brasília.

Galton M.M., Sulzer C.R., Santa Rosa C.A. \& Fields M.J. 1965. Application of a microtechnique to the Agglutination Test for Leptospiral Antibodies. Appl. Microbiol. 13:81-85.

Garcia E.A. \& Castro L.H.R. 1986. Análise da frequência de chuva no Pantanal Mato-Grossense. Pesq. Agropec. Bras. 2:909-925.

Giorgi W., Genovez M.E., Teruya J.M. \& Silva A.S. 1984. Leptospira interrogans, sorotipo Wolffi, isolada de camundongo capturado no porto de Santos, SP. Biológico 50(12):295-297.

Girio R.J.S., Pereira F.L.G., Marchiori Filho M., Mathias L.A., Herreira R.C.P., Alessi A.C. \& Girio T.M.S. 2004. Pesquisa de anticorpos contra Leptospira spp. em animais silvestres ou em estado feral da região da Nhecolândia, Mato Grosso do Sul, Brasil. Utilização da técnica de imuno-histoquímica para detecção do agente. Ciência Rural 34:165-169.

Hashimoto V.Y., Dias J.A., Spohr K.A.H., Silva M.C.P., Andrade M.G.B., Muller E.E. \& Freitas J.C. 2012. Prevalência e fatores de risco associados a Leptospira spp. em rebanhos bovinos da região centro-sul do estado do Paraná. Pesq. Vet. Bras. 32:99-105. 
Homem V.S.F., Heinemann M.B., Moraes Z.M., Vianna M.C.B., Silva J.C.R., Sakamoto S.M., Pinheiro S.R., Veiga J.B., Lau H.D., Quanz D., Tourrand J.F., Ferreira F. \& Ferreira Neto J.S. 2000. Leptospirose bovina em Uruará, PA, município da Amazônia Oriental. Arqs Inst. Biológico, São Paulo, 67(1):1-8.

Levett P.N. 2001. Leptospirosis: a forgotten zoonosis. Clin. Appl. Immunol. Rev. 14(2):296-326.

Lilenbaum W. \& Souza G.N. 2003. Factors associated with bovine leptospirosis in Rio de Janeiro, Brazil. Res. Vet. Sci. 75:249-251.

Lins Z.C., Lopez M.L. \& Maroja O.M. 1986. Bacteriologia: epidemiologia da leptospirose com particular referência à Amazônia brasileira, p.733764. In: Instituto Evandro Chagas (Ed.), 50 Anos de Contribuição às Ciências Biológicas e à Medicina Tropical. Ministério da Saúde, Belém.

Martin S.W., Meek A.H. \& Willeberg P. 1987. Veterinary epidemiology, principles and methods. Iowa State University Press, Ames, Iowa, USA. 343p.

Mathias L.A., Girio R.J.S. \& Duarte J.M.B. 1999. Serosurvey for antibodies against Brucella abortus and Leptospira interrogans in pampas deer from Brazil. J. Wildl. Dis. 35(1):112-114.

Medronho R., Bloch K.V., Luiz R.R. \& Werneck G.L. 2009. Epidemiologia. Atheneu, São Paulo.

Moreira E.C. 1994. Avaliação de métodos para erradicação de Leptospirose de bovinos leiteiros. Tese de Doutorado em Veterinária, Escola de Medicina Veterinária, Universidade Federal de Minas Gerais, Belo Horizonte, MG.

Noordhuizen J.P.T.M., Frankena K., Van Der Hoofd C.M. \& Graat E.A.M. 1997. Application of quantitative methods in veterinary epidemiology. Wageningen Pers, Wageningen. 429p.

Oliveira R.C. 2003. Utilização de estirpe local de Leptospira spp. na prova de soroaglutinação microscópica para a leptospirose canina. Dissertação de Mestrado em Ciência Animal, Centro de Ciências Agrárias, Departamento de Medicina Veterinária Preventiva, Universidade Estadual de Londrina. Londrina, Paraná.

Oliveira F.C.S., Azevedo S.S., Pinheiro S.R., Batista C.S.A., Moraes Z.M., Souza G.O., Gonçales A.P. \& Vasconcellos S.A. 2010. Fatores de risco para a leptospirose em fêmeas bovinas em idade reprodutiva no Estado da Bahia. Pesq. Vet. Bras. 30(5):398-402.
Pellegrin A.O., Sereno J.R.B. \& Figueiredo J.O. 1992. Levantamento sorológico de aglutininas anti-Leptospira em bovinos da sub-região da Nhecolândia, Pantanal Sulmatogrossense. Anais $22^{\circ}$ Congresso Brasileiro de Medicina Veterinária, Curitiba, PR, p.145.

Pellegrin A.O., Guimarães P.H.S., Sereno J.R.B., Figueiredo J.P., Lage A.P., Moreira E.C. \& Leite R.C. 1999. Prevalência da leptospirose em bovinos do Pantanal Mato-Grossense. Comunicado Técnico, Embrapa Pantanal 22:1-9.

Sampaio I.B.M. 1998. Estatística aplicada à experimentação animal. FEPMVZ, Belo Horizonte.

Sarmento A.M.C., Azevedo S.S., Morais Z.M., Souza G.O., Oliveira F.C.S., Gonçalves A.P., Miraglia F. \& Vasconcellos S.A. 2012. Emprego de estirpes Leptospira spp. isoladas no Brasil na microtécnica de soroaglutinação microscópica aplicada ao diagnóstico da leptospirose em rebanhos bovinos de oito estados brasileiros. Pesq. Vet. Bras. 32(7):601-606.

Silva F.J., Conceição W.L.F., Fagliardi J.J., Girio R.J.S., Dias R.A., Borba M.R. \& Mathias L.A. 2012. Prevalência e fatores de risco de leptospirose bovina no Estado do Maranhão. Pesq. Vet. Bras. 32:303-312.

Vasconcellos S.A., Arbarini Junior B.O., Umehara O., Morais Z.M., Cortez A., Pinheiro S.R., Ferreira F., Favero A.C.M. \& Ferreira Neto J.S. 1997. Leptospirose bovina: níveis de ocorrência e sorotipos predominantes em rebanhos dos Estados de Minas Gerais, São Paulo, Rio de Janeiro, Paraná, Rio Grande do Sul e Mato Grosso do Sul, período de janeiro a abril de 1996. Arqs Inst. Biológico, São Paulo, 64:7-15.

Vieira A.S., Rosinha G.M.S., Oliveira C.E.D., Vasconcellos A.S., Lima-Borges P.A., Tomas W.M., Mourão G.M., Lacerda A.C.R., Soares C.O., Araújo F.R., Piovezan U. \& Zucco C.A. 2011. Survey of Leptospira spp. in pampas deer (Ozotoceros bezoarticus) in the Pantanal wetlands of the state of Mato Grosso do Sul, Brazil by serology and polymerase chain reaction. Mem. Inst. Oswaldo Cruz 106(6):763-768.

Vieira A.S., Rosinha G.M.S., Vasconcellos A.S., Morais Z.M., Viana R.C., Oliveira C.E., Soares C.O., Araujo F., Mourão G.M., Bianchi R.C., Olifiers N., Rademaker V., Rocha F.L. \& Pellegrin A.O. 2013. Identificação de mamíferos silvestres do Pantanal sul-mato-grossense portadores de Leptospira spp. Ciênc. Anim. Bras. 14:373-380. 